Journal of

Women's Health and Gynecology

\title{
Condom Knowledge and Negotiation in Women Living with and without Human Immunodeficiency Virus
}

Rachel K. Scott ${ }^{1,2, *}$; Katie P. Friday ${ }^{1}$; Elise Rosenthal ${ }^{3}$; Michelle Darko ${ }^{4}$; Eshetu Tefera ${ }^{4}$

${ }^{1}$ Department of Women's and Infants' Services, MedStar Washington Hospital Center

${ }^{2}$ MedStar Health Research Institute:110 Irving Street NW Washington DC 20010

${ }^{3}$ Albert Einstein College of Medicine, Bronx, NY: 1300 Morris Park Ave, Bronx, NY

${ }^{4}$ SOAR Research Internship Program, Georgetown University, Washington DC Summer program at MWHC

${ }^{*}$ Corresponding author: Rachel K. Scott, MD, MPH; 110 Irving Street NW; Suite 5B-18 Washington, District of

Columbia 20010; E-mail: rachel.k.scott@medstar.net

Received Date: February 1, 2017; Accepted Date: March 20, 2017; Published Date: March 22, 2017

Citation: Rachel K. Scott, et al. (2017) Condom Knowledge and Negotiation in Women Living with and without Human Immunodeficiency Virus. J Womens Health Gyn 1: 1-8.

\begin{abstract}
Objective: To assess condom and sexual knowledge, condom use and negotiation tactics of HIV positive and negative women, and identify any unmet need for education.

Methods: We compiled the survey instrument from previously psychometrically validated questions, including condom knowledge, use, and negotiation skills. We recruited a convenience sample from the Obstetrics and Gynecology and Infectious Disease Clinic waiting rooms. In our analysis, we used descriptive statistics: T-tests, Wilcoxon rank sum, Chi-square and Fisher exact tests and multivariate logistic regression.

Results: We collected 438 questionnaires; 114 respondents were HIV positive. Median age was 39.6 and the majority were African American (87.9\%). HIV positive women had lower levels of education and income, but higher number of lifetime sexual partners and pregnancies. HIV positive women were more likely to report condom use ( $80 \%$ vs. $45.4 \% \mathrm{p}=0.0001)$ and consistent condom use; $71 \%$ reporting "most of the time" or "always" vs. $43.3 \%$ ( $\mathrm{p}=0.0001$ ). Only $53.2 \%$ of HIV negative women and $75.4 \%$ of HIV positive women reported negotiating condom use when their partner declined ( $<0.0001)$. HIV positive women were more likely to report using condom negotiation strategies such as autocracy, bargaining, bullying, disengagement, manipulation, and supplication.
\end{abstract}

Conclusions: HIV positive women reported increased condom knowledge, use and negotiation skills compared to their HIV negative counterparts. Gaps in knowledge, condom use, and negotiation skills highlight need for further education and empowerment of women with and without HIV to prevent spread of HIV in this high-prevalence, high-risk population.

Keywords: Condom Knowledge; Condom Negotiation; HIV

Capsule: HIV positive women reported increased condom knowledge, use, and negotiation skills compared to their HIV negative counterparts, highlighting the need for further education and empowerment of women with and without HIV to prevent spread of HIV.

C 2017 The Authors. Published by the JScholar under the terms of the Creative Commons Attribution License http://creativecommons.org/licenses/ by $/ 3.0 /$, which permits unrestricted use, provided the original author and source are credited. 


\section{Introduction}

In 2009, an estimated 11,200 women were newly infected with Human Immunodeficiency Virus (HIV) in the United States; women of reproductive age comprised one quarter of these new diagnoses [1]. Seventy-two percent of these newly diagnosed HIV cases were transmitted through heterosexual sex [2]; risk factors included being unaware of one's partner's HIV status and unprotected vaginal sexual intercourse[1] The same high risk sexual behaviors through which women contract HIV also put them at high risk for other sexually transmitted infections (STIs).

Every year, an estimated 20 million new STIs are reported in the United States [3]. The incidence continues to rise steadily with an eight-percent increase in Chlamydia and four-percent increase in Gonorrhea from 2010 to 2011 alone [4]. STIs have not only acute, but also long-term health consequences. Gonorrhea and Chlamydia cause not only cervicitis, but also pelvic inflammatory disease, preterm labor, chronic pelvic pain, and sterility secondary to tubal scarring [5]. These infections not only have health consequences for individual women; STIs burden cost the US medical system with approximately $\$ 16$ billion per year in health care costs [3].

Both HIV and STIs disproportionately affect minority women. The rate of new HIV infections among African American and Hispanic women are 20 times and 4 times that of white women respectively [1]. STIs are diagnosed at 30 times the rate in African American women age of 15-19 than white women in the same age group [4]. Condoms, when used correctly, are highly effective in preventing the transmission of HIV and STIs. According to the World Health Organization, the male latex condom is the single most efficient available technology to reduce the sexual transmission of HIV and other sexually transmitted infections [6]. Proper use has been shown to decrease HIV transmission by $80 \%$ [7] and HPV transmission by 70\%, [8] however most patients do not use condoms properly. A systematic review found that incomplete use (such as late application or early removal) occurred $17.0 \%$ to $51.1 \%$ of the time, while other improper techniques (like leaving no space at the tip) ranged from $24.3 \%$ to $45.7 \%$ [9].

Patients must not only use condoms properly for them to be effective, but they must use them consistently. A recent survey found that only $21.8 \%$ of women used a condom during their last sexual encounter [10]. Several studies have identified barriers to consistent and correct condom use, specifically partner preference [11], physical and emotional violence, $[1,12]$ limited sexual knowledge,13,14 and weak/limited negotiation strategies [13-15]. Proven motivators of condom use among females include gender empowerment, [16,17] HIV and STI knowledge [13-15], and well developed communication skills and negotiation strategies $[13,14]$. Women who are HIV positive report more consistent condom use than their HIV negative counterparts. The WiLLOW trial found that $51.7 \%$ to $72.2 \%$ of HIV positive women used a condom during their last sexual encounter [18]. Although HIV positive women are more consistent in their use of condoms, they share similar barriers and motivators with their HIV negative counterparts $[18,19]$.
In the District of Columbia, the incidence of HIV and STIs is significantly higher than the national average. The rate of Chlamydia among women in the district is 1,372 per 100,000 and 380.3 per 100,000 for gonorrhea [4]. HIV infections among women is $1,422.4$ per 100,000 [20], compared to the national average of 7.7 per 100,000 [21]. Given concern for the STI and HIV epidemic in our community, our research team set out to identify barriers to condom use in our clinic population. Our goal was to gather baseline information to then design an intervention to promote safer sexual practices to prevent the spread of sexually transmitted infections and HIV in our high-risk population. Specifically, we aimed to investigate safe sexual practices knowledge, condom use, sexual behavior, and condom negotiation skills in this high-risk population. We hypothesized that HIV positive women would have limited sexual and condom knowledge, but superior knowledge compared to their HIV negative counterparts-- secondary to their additional HIV-related medical care. We further hypothesized, that HIV positive women would have low but more consistent use of condoms compared to their HIV negative counterparts, again secondary to the emphasis on condom use in their medical visits. And finally that, HIV positive women would have commensurate condom negotiation skills to their HIV negative counterparts, as this is not traditionally emphasized in health education counseling for either group.

\section{Materials and Methods}

To test our hypothesis we designed a questionnaire that incorporated both previous psychometrically validated questions from several studies $[14,16,19,22]$ and questions designed to gather information about our particular population's demographics and medical history. The questionnaire consisted of five sections: Demographics, Obstetrical History, Sexual History, Sexual Knowledge, and Condom Negotiation Strategies with a total of 31 questions. Question types included cafeteria questions, True/False, and fill in the blank. The MedStar Health Research Institute Institutional Review Board (IRB) approved the study prior to initiation.

We recruited a convenience sample of women from the MedStar Washington Hospital Center outpatient Obstetrics and Gynecology Clinic and Infectious Disease Clinics, with the goal of recruiting $108 \mathrm{HIV}$ positive and $324 \mathrm{HIV}$ negative patients based on an a priori power calculation. All females in the respective waiting rooms were invited to participate in the survey. Members of the research team distributing surveys were not aware of participants' HIV status or reason for their visit. The research team obtained a verbal informed consent from all participants and distributed the printed objectives of the study and a copy of the consent. The survey was taken in private. $\mathrm{Pa}$ tients received a $\$ 10$ gift card for their participation. The data from the completed surveys were entered into a password protected electronic database. The data entered was double checked by a second reviewer for accuracy. 
For the condom negotiation portion of the survey, participants were asked to circle any verbal statements they had used during negotiation of condom use with a partner. These statements were selected to represent the different type of tactics, specifically autocracy, bargaining, bullying, disengagement, manipulation, and supplication [15]. We then broke down negotiation skills into three subcategory levels: high, medium, and low. If a participant reported having used between 0 and 2 tactics, they were considered low, between 3 and 5: medium, and 6 to 8 statements high or superior in their use of condom negotiation tactics.

We used descriptive statistics to describe study subjects' characteristics such as age, gender, race, marital status and income. We used means and standard deviations to describe continuous variables. To examine differences in the averages between the two groups if normality assumption satisfied, we used two sample t-test and the non parametric Wilcoxon rank sum test when normality assumption was not satisfied. We used frequencies and percentages to describe categorical variables and Chi-square and Fisher exact tests, as appropriate, to investigate differences. We used logistic regression analysis to examine the relationship between binary outcome variables and the explanatory variables adjusting for potential confounding variables. We used the standard $p$-value of $<.05$ to indicate a significant difference. Statistical Analysis System software version 9.3 (Cary, North Carolina) was used to perform the analysis.

Sample size calculations were based on previous studies. We estimated an effect size of $17 \%$ difference in sexual, condom knowledge and consistency of condom use between HIV positive and HIV negative women. We projected that a total sample of 432 participants (108 HIV positive and 324 HIV negative) would have sufficient power $(0.80)$ to detect the specified effect.

\section{Results}

Out of the 496 women approached, we collected 438 completed questionnaires. One hundred and fourteen respondents were HIV positive. The majority of the participants were African American (87.9\%) and median age was 39.6, consistent with the outpatient clinic population. As demonstrated in Table 1, there were no significant differences in age, race, marital status, or source of income between HIV positive and negative survey participants. HIV positive women had lower levels of education and income, specifically $71 \%$ of HIV positive women reported an income of $\$ 29,999$ or less compared to $61 \%$ of HIV negative women and $62 \%$ of HIV positive reported completing high school or less, compared to $48 \%$ of HIV negative women. HIV positive women reported higher number of lifetime sexual partners and pregnancies: on average, HIV positive women had 7.6 sexual partners compared to 5.8 , and 4 total pregnancies compared to 3.1 , respectively.
Table 1: Demographics for Survey Participants

\begin{tabular}{|c|c|c|c|}
\hline & $\begin{array}{l}\text { HIV negative } \\
\mathrm{N}=324\end{array}$ & $\begin{array}{l}\text { HIV positive } \\
\mathrm{N}=114\end{array}$ & $\begin{array}{l}\mathrm{p} \text { value } \\
<0.05\end{array}$ \\
\hline Age & $39.1 \pm 15.1$ & $41.3 \pm 12.6$ & 0.089 \\
\hline Race & & & 0.359 \\
\hline Hispanic & $10(3.1)$ & $1(0.9)$ & \\
\hline Black & $279(86.1)$ & $106(93.0)$ & \\
\hline White & $13(4.0)$ & $1(0.9)$ & \\
\hline Asian & $2(0.6)$ & $1(0.9)$ & \\
\hline $\begin{array}{l}\text { Native Ameri- } \\
\text { can }\end{array}$ & $1(0.3)$ & $0(0.0)$ & \\
\hline Other/multiple & $19(5.9)$ & $5(4.4)$ & \\
\hline Marital Status & & & 0.457 \\
\hline $\begin{array}{l}\text { Married, living } \\
\text { together }\end{array}$ & $59(18.2)$ & $12(10.6)$ & \\
\hline $\begin{array}{l}\text { Married, sepa- } \\
\text { rated }\end{array}$ & $15(4.6)$ & $5(4.4)$ & \\
\hline Divorced & $23(7.1)$ & $8(7.1)$ & \\
\hline Widowed & $16(4.9)$ & $3(2.7)$ & \\
\hline $\begin{array}{l}\text { Living with boy- } \\
\text { friend or partner }\end{array}$ & $40(12.4)$ & $14(12.4)$ & \\
\hline Single & $167(51.5)$ & $70(62.0)$ & \\
\hline Other & $4(1.2)$ & $1(0.9)$ & \\
\hline Education & & & 0.043 \\
\hline $\begin{array}{l}\text { 11th grade or } \\
\text { less }\end{array}$ & $39(12.1)$ & 21(18.8) & \\
\hline $\begin{array}{l}\text { High School } \\
\text { graduate/GED }\end{array}$ & $118(36.5)$ & $49(43.8)$ & \\
\hline Some college & $108(33.4)$ & $31(27.7)$ & \\
\hline $\begin{array}{l}\text { Completed } 4 \\
\text { year college }\end{array}$ & $58(18.0)$ & $11(9.8)$ & \\
\hline \multicolumn{4}{|l|}{ degree or more } \\
\hline Income & & & 0.034 \\
\hline$\$ 0$ - $\$ 19,999$ & $132(42.6)$ & $63(55.8)$ & \\
\hline $\begin{array}{l}\$ 20,000- \\
\$ 29,999\end{array}$ & $57(18.4)$ & 18(15.9) & \\
\hline $\begin{array}{l}\$ 30,000 \\
-\$ 54,999\end{array}$ & $70(22.6)$ & $24(21.2)$ & \\
\hline$\$ 55,000$ or more & $51(16.5)$ & $8(7.1)$ & \\
\hline
\end{tabular}




\begin{tabular}{|c|c|c|c|}
\hline $\begin{array}{l}\text { Main course of } \\
\text { financial sup- } \\
\text { port }\end{array}$ & & & 0.150 \\
\hline $\begin{array}{l}\text { Own job or } \\
\text { Salary }\end{array}$ & $122(38.4)$ & $34(30.4)$ & \\
\hline Public assistance & $103(32.4)$ & $49(43.8)$ & \\
\hline $\begin{array}{l}\text { Someone else's } \\
\text { job }\end{array}$ & $28(8.8)$ & $10(8.9)$ & \\
\hline Multiple source & $26(8.2)$ & $11(9.8)$ & \\
\hline Other & $39(12.3)$ & $8(7.1)$ & \\
\hline $\begin{array}{l}\text { Number of } \\
\text { pregnancies }\end{array}$ & $3.1 \pm 2.5$ & $4.0 \pm 2.9$ & 0.002 \\
\hline $\begin{array}{l}\text { Number of } \\
\text { unplanned } \\
\text { pregnancies }\end{array}$ & $0.8 \pm 1.4$ & $1.1 \pm 1.7$ & 0.175 \\
\hline Living Children & $1.7 \pm 1.6$ & $2.3 \pm 1.9$ & 0.009 \\
\hline $\begin{array}{l}\text { Number of } \\
\text { Abortions }\end{array}$ & $0.7 \pm 1.3$ & $0.8 \pm 1.3$ & 0.986 \\
\hline $\begin{array}{l}\text { Number of } \\
\text { Miscarriages }\end{array}$ & $0.4 \pm 0.9$ & $0.6 \pm 1.2$ & 0.260 \\
\hline $\begin{array}{l}\text { Number of Ec- } \\
\text { topic Pregnan- } \\
\text { cies }\end{array}$ & $0.1 \pm 0.2$ & $0.1 \pm 0.3$ & 0.261 \\
\hline $\begin{array}{l}\text { Age first vaginal } \\
\text { sex }\end{array}$ & $16.5 \pm 3.2$ & $16.0 \pm 4.0$ & 0.031 \\
\hline $\begin{array}{l}\text { Number of } \\
\text { partners }\end{array}$ & $5.8 \pm 7.4$ & $7.6 \pm 9.1$ & 0.017 \\
\hline
\end{tabular}

Eighty-percent of HIV positive women reported any condom use compared to only $45 \%$ of HIV negative women $(\mathrm{p}<0.0001)$. When asked if they had every negotiated condom use, only $53.2 \%$ of HIV negative women reported past condom negotiation, compared to $75.4 \%$ of HIV positive women.

When comparing negotiation skills, HIV positive women were more likely to use all tactics compared to HIV negative women. (Table 2) For autocracy, we used the sample statement "I don't want to have a baby." Twenty-nine percent of HIV positive women were more likely autocracy compared to HIV negative women. For bargaining, we used two sample statements: "But we could get pregnant" and "We need to use a condom to be safe." There was no statistical difference in use of "we could get pregnant" between the two groups, however, $60.5 \%$ of HIV positive women selected "we need to use a condom to be safe," compared to $32.4 \%$ of HIV negative women. HIV positive women were also more likely to select both statements representing bullying, with $44.7 \%$ (vs. $25.9 \%$ ) selecting "Here is a condom," and $28.1 \%$ (vs. 6.2\%) "Just put a condom on him without saying anything." Forty-five percent of HIV positive women, compared to $27.5 \%$ of HIV negative, selected the statement "I will not have sex without a condom," representing the disengagement tactic.

For manipulation, we used the sample statement of "I have an STD," for which $10.5 \%$ of HIV positive women selected compared to $4.3 \%$ of HIV negative women. Lastly, $45.6 \%$ of HIV positive women compared to $25.3 \%$ of HIV negative women selected "Do you have a condom?" which represented supplication. There was no statistical correlation between negotiation tactics and sexual and condom knowledge, even when controlling for HIV status.

Table 2: Negotiation Tactics of Survey Participants

\begin{tabular}{|c|c|c|c|}
\hline & $\begin{array}{l}\text { HIV Nega- } \\
\text { tive }\end{array}$ & $\begin{array}{l}\text { HIV posi- } \\
\text { tive }\end{array}$ & $\begin{array}{l}\mathrm{p} \text { value } \\
<0.05\end{array}$ \\
\hline \multicolumn{4}{|l|}{ Autocracy } \\
\hline $\begin{array}{l}\text { "I don't want to } \\
\text { have a baby." }\end{array}$ & $60(18.5)$ & $34(29.8)$ & 0.0114 \\
\hline \multicolumn{4}{|l|}{ Bargaining } \\
\hline $\begin{array}{l}\text { "But we could } \\
\text { get pregnant." }\end{array}$ & $70(21.6)$ & $30(26.3)$ & 0.3027 \\
\hline $\begin{array}{l}\text { "We need to use } \\
\text { a condom to be } \\
\text { safe." }\end{array}$ & $105(32.4)$ & 0.3027 & $<0.0001$ \\
\hline \multicolumn{4}{|l|}{ Bullying } \\
\hline $\begin{array}{l}\text { "Here is a con- } \\
\text { dom." }\end{array}$ & $84(25.9)$ & $51(44.7)$ & 0.0002 \\
\hline $\begin{array}{l}\text { Just put a } \\
\text { condom on him } \\
\text { without saying } \\
\text { anything. }\end{array}$ & $20(6.2)$ & $32(28.1)$ & 0.0004 \\
\hline \multicolumn{4}{|l|}{ Disengagement } \\
\hline $\begin{array}{l}\text { "I will not have } \\
\text { sex without a } \\
\text { condom." }\end{array}$ & $89(27.5)$ & $52(45.6)$ & 0.0004 \\
\hline \multicolumn{4}{|l|}{ Manipulation } \\
\hline "I have a STD." & $14(4.3)$ & $12(10.5)$ & 0.0159 \\
\hline \multicolumn{4}{|l|}{ Supplication } \\
\hline $\begin{array}{l}\text { "Do you have a } \\
\text { condom?" }\end{array}$ & $82(25.3)$ & $52(45.6)$ & $<0.0001$ \\
\hline
\end{tabular}

Women with HIV were more likely to answer questions correctly regarding sexual knowledge. The questions in which they statistically differed were in identifying ways of prevention and transmitting HIV. Seventy-six-percent of HIV negative women could correctly identify HIV as a sexually transmitted infection compared to $92.1 \%$ of HIV positive women. (Figure 1) When specifically asked, "How one could be infected with HIV?" only $84 \%$ of HIV negative women, compared to $94 \%$ of HIV positive women, correctly selected vaginal intercourse. In comparison, $14.9 \%$ of HIV negative women incorrectly selected kissing as a mode of transmission, compared to $1.4 \%$ of HIV positive women. (Figure 2) When asked in ways one could prevent HIV transmission, $79.3 \%$ of HIV negative women correctly selected condoms, compared to $93 \%$ of HIV positive women (Figure 3 ). 
Figure 1:

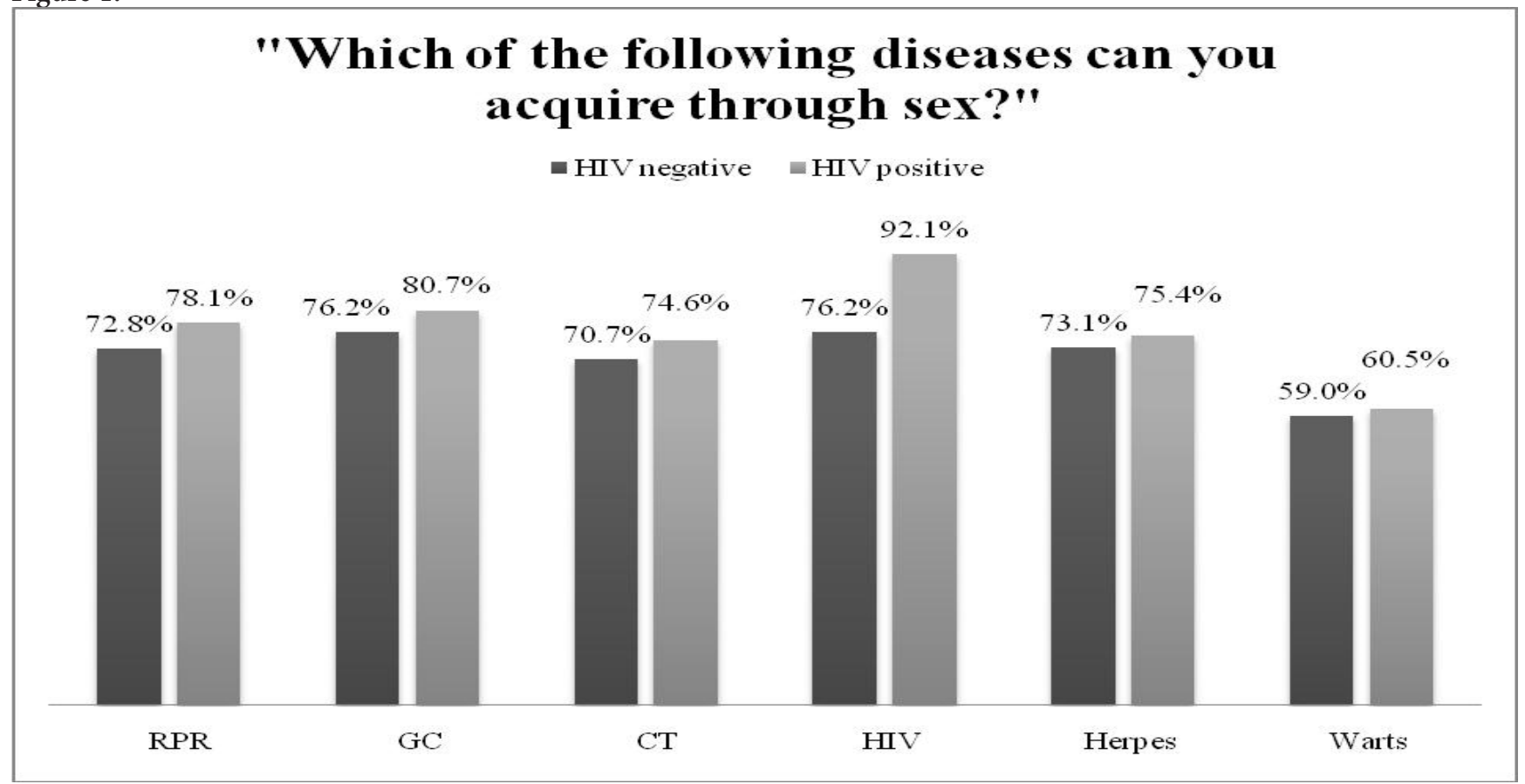

Figure 2:

\section{"How can you be infected with HIV?"}

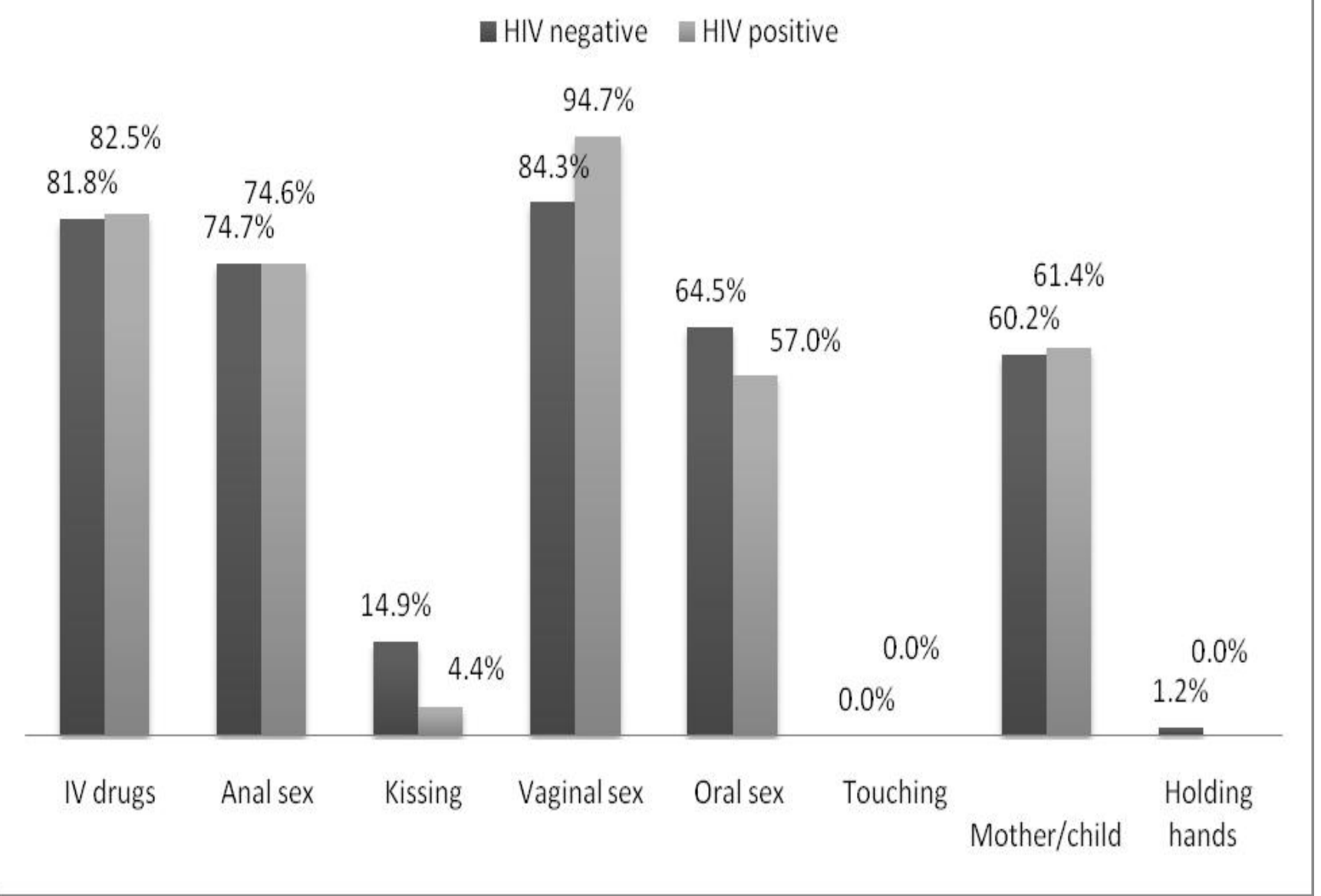


Figure 3:

\section{"You can prevent HIV by":}

HIV negative HIV positive

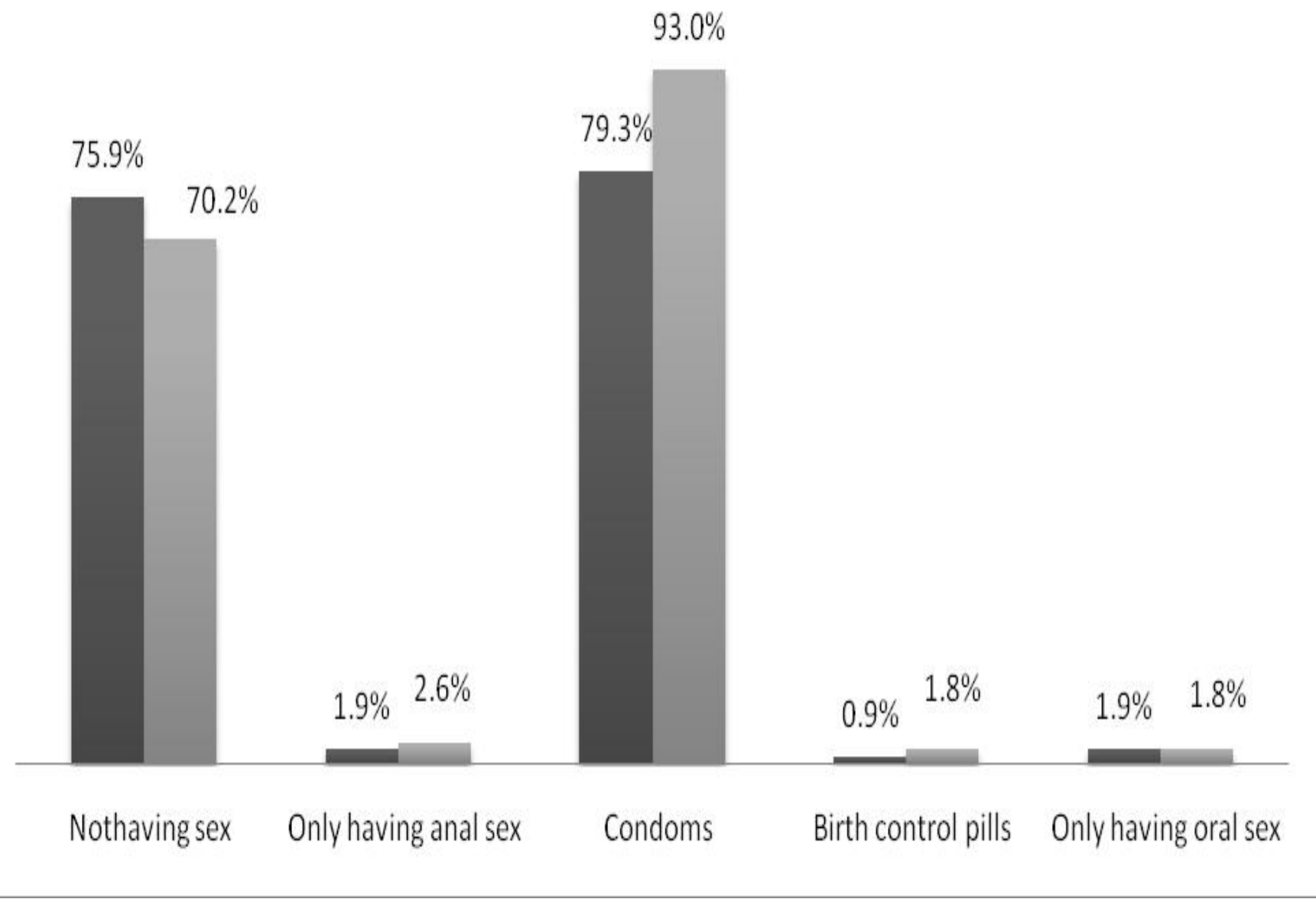

We examined associations between condom negotiation skills and sexual and condom knowledge. We observed trends towards associations between low negotiation skills (selecting 2 or less statements) and lower sexual and condom knowledge, however, no direct correlations could be made. This was the same for all participants regardless of HIV status.

We performed a multivariate logistic regression taking into account the statistically significant differences in education, income, number of pregnancies, and sexual partners between the cohorts regarding sexual knowledge and condom use without an impact on the above results. There were, however, non-statistically significant trends toward less sexual and condom knowledge with lower income and education status. When we controlled for length of relationship with partner and use of other forms of birth control, we did see that women, regardless of HIV status, were more likely to use other forms of birth control if they had been with a partner for 1 year or longer, but less likely to use a condom if they had been with a partner for 1 year or longer (69.4\% and 78.0\%).

\section{Discussion}

This study demonstrated concerningly low proportions of condom use, low levels of sexual and condom knowledge, and low condom negotiation skills among HIV positive and HIV negative women. As we hypothesized, HIV positive women reported more consistent use of condoms compared to their HIV negative counterparts, although much lower than ideal. After controlling for education, income, number of pregnancies, and number of sexual partners, we found no difference in condom use, although we were likely underpowered to show significant differences in these variables. We also found that not using a condom was associated with both being in a relationship of greater than one year and with using another method of birth control for pregnancy prevention. 
We found that HIV positive women had superior sexual and condom knowledge compared to women without HIV, likely attributable to the emphasis on barrier contraception in their HIV medical care. This said, across the board condom and sexual knowledge were lower than ideal and speak to an unmet need for sexual education for women.

We hypothesized that there would be no difference in condom negotiation skills between HIV positive and HIV negative women; however, we found that HIV positive women had sub-optimal but superior condom negotiation skills compared to their HIV negative counterparts. This, again, is likely secondary to the additional medical care and support HIV positive patients received after diagnosis-or possibly motivated by HIV positive women's past experience contracting HIV or desire to protect their partners. The results speak to an unmet need for education and empowerment: half of HIV negative women and a quarter of HIV positive women reported never having negotiated condom use when a partner did not want to use a condom.

Strengths of our study include large sample size and generalizability to other urban resource-rich settings. We were sufficiently powered to detect the specific effect size in regards to HIV status. Given the demographics of the participants, we were able to capture a patient population that one would see in most large urban areas of the United States. We initially designed this study to focus on HIV positive women, using HIV negative women as a comparison group. Given this perspective, we failed to inquire if the HIV negative women's partners' sero-status was known and if he/she was HIV positive or negative, and its relation to consideration in condom use and negotiation. We also failed to inquire if patients were actively trying to conceive, which also would impact condom use as it would inherently prevent conception. Although we were powered to show differences by HIV status, we were unable to draw statistically significant conclusions regarding difference in education, income, and number of sexual partners.

\section{Conclusions}

This study revealed critical gaps in knowledge, condom use, and negotiation skills and highlights the unmet need for interventions to further educate and empower women with and without HIV to prevent spread of HIV in this high-prevalence, high-risk population.

\section{Acknowledgements}

Funding from MedStar Graduate Medical Education Research Fund

\section{References}

1) Centers for Disease Control and Prevention. (2011). HIV in Women

2) Gynecologic care for women with human immunodeficiency virus (2010) Practice Bulletin No. 117. ACOG Committee on Practice Bulletins--Gynecology. Obstet Gynecol 16: 1492-1509.

3) Centers for Disease Control and Prevention. (2013) Incidence, Prevalence, and Cost of Sexually Transmitted Infections in the United States.

4) Centers of Disease Control and Prevention (2011). Sexually Transmitted Diseases Surveillance.

5) Rock, JA \& Jones HW (2011) Pelvic Inflammatory Disease. In TeLinde's Operative Gynecology (10th edn,) Philadelphia, USA: Wolters Kluwer.

6) Condoms and HIV Prevention. Position statement by WHO, UNAIDS, and UNFPA. WHO; originally published in2004, updated 2009.

7) Weller. S, Davis. K ( 2002) Condom effectiveness in reducing heterosexual HIV transmission. Cochrane Database Syst Rev Issue 1. Art. No.: CD003255.

8) Winer RL, Hughes JP, Feng Q, O’Reilly S, Kiviat NB, et al. (2006) Condom use and the risk of genital human papillomavirus infection in young women. N Engl J Med 354: 2645-2654.

9) Sanders SA, Yarber WL, Kaufman EL, Crosby RA, Graham CA, et al. (2012) Condom use errors and problems: a global view. Sexual Health. 9: 81-95.

10) Sanders SA, Reece M, Herbenick D, Schick V, Dodge B, et al. (2010) Condom use during most recent vaginal intercourse event among a probability sample of adults in the United States. J Sex Med 5: 362-373.

11) Noar SM, Crosby R, Benac C, Snow G, Troutman A ( 2011) Application of attitude-social influence-efficacy model to condom use among African-American STD clinic patients: implications for tailored health communication. AIDS Behav 15: 1045-1057.

12) Sobo EJ (1993) Inter-city women and AIDS: The psycho-social benefits of unsafe sex. Cult Med Psychiatry 17: 455-485.

13) Chin HB, Sipe TA, Elder R, Mercer SL, Chattopadhyay SK, et al.(2012) The effectiveness of group-based comprehensive risk-reduction and abstinence education interventions to prevent or reduce the risk of adolescent pregnancy, human immunodeficiency virus, and sexually transmitted infections. Am J Prev Med. 42: 272- 294.

14) Peragallo N, Gonzalez-Guarda RM, McCabe BE, Cianelli R (2012) The efficacy of an HIV risk reduction intervention for Hispanic women. AIDS Behav 16: 1316-1326

15) Otto-Salaj LL, Traxel N, Brondio MJ, Reed B, Gore-Felton C,et al (2010) Reactions of heterosexual African-American men to women's condom negotiation strategies. J Sex Res. 47 : 539-551.

16) French SE, Holland KJ (2013) Condom negotiation strategies as a mediator of the relationship between self-efficacy and condom use. J Sex Res. 1: 48-59.

17) Kennedy BR, Jenkins CC (2011) Promoting African American women and sexual assertiveness in reducing HIV/AIDS: an analytical review of the research literature. J Cult Divers 18: 142-149.

18) Wingood GM, DiClemente RJ, Mikhail I, Lang DL, McCree DH, et al. (2004) A Randomized Controlled Trial to Reduce HIV Transmission Risk Behaviors and Sexually Transmitted diseases Among Women Living with HIV: The WiLLOW Trial. J Acquir Immune DeficSyndr 37 : S58- S67. 
19) Lang DL, Salazar LF, Wingood GM, DiClemente RJ, Mikhail I, et al. (2007) Associations between gender-based violence and pregnancy, sexually transmitted infections, condom use practices, and negotiation of sexual practices among HIV-positive women. J Acquir Immune DeficSyndr 46:216-221.

20) Department of Health: District of Columbia. (2011). Annual Report 2011.

21) Centers of Disease Control and Prevention (2011) HIV/AIDS Statistics and Surveillance.

22) Carey MP, Schroder KEE (2002) Development and Psychometric Evaluation of the Brief HIV Knowledge Questionnaire. AIDS Educ Prev 14: 172-182.

Submit your manuscript to a JScholar journal and benefit from:

ब Convenient online submission

ๆ Rigorous peer review

9 Immediate publication on acceptance

I Open access: articles freely available online

q High visibility within the field

I Better discount for your subsequent articles

Submit your manuscript at http://www.jscholaronline.org/submit-manuscript.php 